\title{
Identifying Natural Therapeutics against Diabetes via Inhibition of Dipeptidyl Peptidase 4: Molecular Docking and MD Simulation Study
}

\author{
Mohd Adnan Kausar ${ }^{1, \star}$, SMA Shahid ${ }^{1}$, Sadaf Anwar ${ }^{1}$, Mohammed Kuddus ${ }^{1}$, Mohammad Kalim Ahmad \\ Khan $^{2}$, Abdullah Dakheel Alotaibi ${ }^{3}$, Jamal Mohammad Arif ${ }^{4}$
}

${ }^{1}$ Department of Biochemistry, College of Medicine, University of Ha'il, Hail, SAUDI ARABIA.

${ }^{2}$ Department of Bioengineering, Integral University, Lucknow, Uttar Pradesh, INDIA.

${ }^{3}$ Department of Otolaryngology Head and Neck Surgery, College of Medicine, University of Ha'il, Hail, SAUDI ARABIA.

${ }^{4}$ Department of Biochemistry, College of Medicine, Shaqra University, Shaqra, SAUDI ARABIA.

\begin{abstract}
Background: As per the International Diabetes Federation statistics 2019, about 463 million people aged between 20-79 years have diabetes, in which mortality of 1.6 million individuals have been recorded each year, especially in developing and economically impoverished countries. Despite the people's equal access to basic facilities of appropriate healthcare systems and lifesaving drugs, it is desirable to accelerate the identification and development of natural drug candidates, prophylactically and therapeutically promising against the disease, thereby strengthening universal health coverage of Sustainable Development Goals. Materials and Methods: The research aims to identify natural inhibitor molecules targeting dipeptidyl peptidase 4 using docking and molecular dynamics simulation studies followed by metabolism and biological activity prediction. Data set of sixteen natural molecules considered to perform molecular interaction studies using AutoDock Tools. Results: Sitagliptin exhibited stronger binding ( $\Delta \mathrm{G}:-8.63$ $\mathrm{kcal} / \mathrm{mol}, \mathrm{Ki}: 10.12 \mu \mathrm{M}$ ) with dipeptidyl peptidase 4 among their all-known inhibitors. Among natural compounds, apigenin, bromelain, cholecalciferol, isoimperatorin, luteolin, neohesperidin, oleanoic acid depicted excellent binding affinities with the target in comparison to sitagliptin as reflected by their $\Delta \mathrm{G}(>-9 \mathrm{kcal} / \mathrm{mol})$ values. The top two ligands-neohesperidin ( $\Delta \mathrm{G}:-9.86 \mathrm{kcal} / \mathrm{mol})$ and bromelain $(-9.79 \mathrm{kcal} / \mathrm{mol})$, and the $\mathrm{known}$ drug sitagliptin was selected for molecular dynamics (MD) simulation to assess stabilities of their docked complexes. Conclusion: Post analysis of MD study, CYP450 metabolism prediction and biological activity spectrum identification favour the antidiabetic potential of bromelain.
\end{abstract}

Key words: Diabetes, Dipeptidyl peptidase 4, Natural therapeutics, Molecular docking, MD simulation, Sustainable development goals.

\section{INTRODUCTION}

Diabetes is one of the most pervasive noncommunicable maladies exhibiting increased blood glucose levels. The persistence of diabetes over a long period leads towards irreparable damage of vital organs of biological systems viz., eyes, kidneys, heart, blood vessels, and neurons. The occurrence of three types of diabetes is shared among various populations globally. Type 1 is also known as insulin-dependent or juvenile diabetes, in which the functioning of the pancreas is impeded to produce insulin due to an autoimmune mechanism. About 5-10\% of individuals, especially kids, teens, and youngsters, have type 1 diabetes worldwide. Type 2, deadliest form of diabetes in which an adequate amount of insulin is produced by the pancreas, but patients cannot utilize it properly, leading to hyperglycemic conditions. Approximately $90-95 \%$ of the population have been diagnosed with type 2 globally, even though it takes a long time
Submission Date: 06-07-2021; Revision Date: 15-10-2021; Accepted Date: 03-01-2022.

DOI: 10.5530/ijper.56.1s.39 Correspondence:

Dr. Mohd Adnan Kausar Department of Biochemistry, College of Medicine, University of Hail-2440, Hail, KSA.

E-mail: adnankausar1@ gmail.com

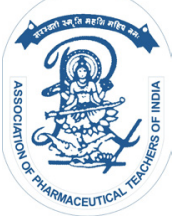

www.ijper.org 
to develop in children, adolescents, and young adults. The third type is gestational diabetes occurring in pregnant women. It might be possible that women get rid of such conditions after the birth of the baby. Such children are prone to amputation and occurrence of type 2 diabetes at a later stage of their life. Apart from the mentioned types, an intermediate condition between healthy and diabetic patients has been seen as impaired glucose tolerance (IGT) and impaired fasting glycemia (IFG). Individuals suffering from IGT and IFG are at higher risk of developing type 2 diabetes during their life span. ${ }^{1-5}$

The incidence of diabetes is growing exponentially and occupies among the top 10 killers of people globally. Patients living with diabetes are in danger of fostering various genuine and perilous inconveniences, prompting critical health care requirements, anxiety towards perishing enjoyable living hood, and undue burden on families and society. The cumulative efforts of the United Nations and WHO have synchronized and implemented the policies of Sustainable Development Goals (SDG) to accelerate and hone the universal health care systems, thereby curtailing 30\% premature death from non-infectious disease by 2030 worldwide. The increased diabetes type 2 is fuelled by various cumulative factors viz., socioeconomic status, sedentary lifestyle, demographic and environmental factors, increasing urbanization, and genetic predisposition. ${ }^{6}$ The contributory factors for enhanced prevalence of gestational and type 1 diabetes are not well established, but their increased cases are also alarming. The global prevalence of diabetes gap in rural $(7.2 \%)$ and urban areas $(10.8 \%)$ are steeply narrowing due to adopting modernized lifestyles. ${ }^{7-9}$ From the most recent couple of years, the inescapability of diabetes type 2 in the Middle East, especially in Saudi Arabia, is growing at a startling rate. Generally, one-fourth of the grown-up populace is influenced by type 2 diabetes, which is further anticipated to increase in the coming days dramatically. Previous thirty years' data reveals that the current increment of diabetes in Saudi Arabia is almost ten folds which is a very alarming situation for healthcare systems. ${ }^{10}$

The occurrence of diabetes in 2019 and estimated incidences in 2030 and 2045 as per the International Diabetes Federation (IDF) is illustrated in Figure 1 (https://idf.org/).

Diabetes type 2, commonly known as diabetes mellitus type 2 (DM2), exacerbates blood glucose level even though ample insulin production from beta cells of the pancreatic island of Langerhans, causing irregularities in vascular systems and other jeopardized biological systems that later build resorts for various diseases. Despite

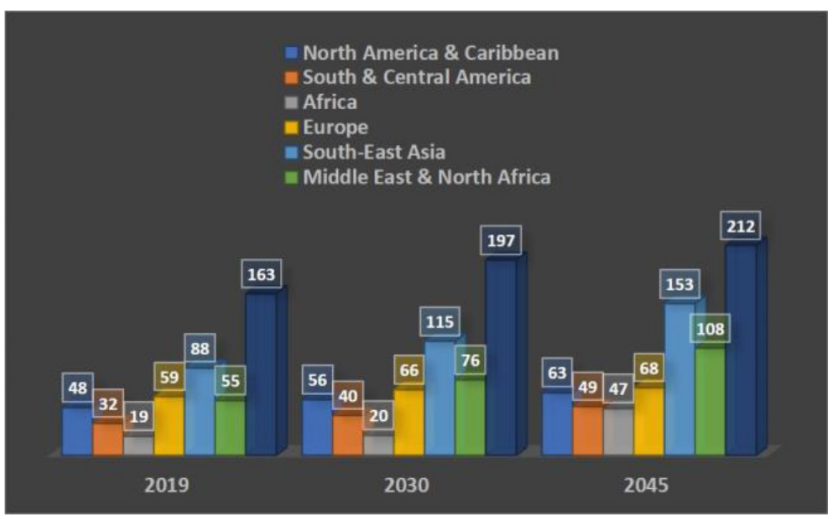

Figure 1: Comparative statistics of diabetic patients in 2019, 2030, and 2045 aged between 20-79 years. The number of occurrences and projections shown on columns is designated in million. ${ }^{6}$

the availability of many preventive and therapeutic medicines, it is a Herculean task to find total control and cure DM2. ${ }^{11}$ For the past few decades, pharmaceutical sectors have been gaining significant attention towards deciphering therapeutically efficacious molecular targets using hybrid approaches of genomics, proteomics, system biology, and traditional experimental biomedical sciences. However, albeit the boom of innovation in high-throughput technology, the functioning of research and development has been honed slowly, resulting in delayed outcomes, especially in drug discovery and development. For example, identifying a new bioactive compound from thousands of lead molecules takes about ten years and costing about $\$ 2-3$ billion, including bench work to clinical trials, regulatory approval, and delivery to the market. Biomolecular modeling, machine learning, artificial intelligence, and computer-aided drug design (CADD) can speed up the process, reduce surprises and predict the properties, thereby reducing the time and cost of R\&D as well. ${ }^{12}$

Dipeptidyl peptidase 4 (DPP IV), an emerging therapeutic target, was taken to identify natural phytochemicals as potential inhibitor molecules. ${ }^{13,14} \mathrm{DPP}$ IV works by deactivating incretins, a group of metabolic hormones of the gastrointestinal tract that responsible for insulin release at physiological $\mathrm{pH}$. Gastric inhibitory peptides, better known as glucodependent insulinotropic polypeptide (GIP) and glucagon-like peptide-1 (GLP-1), two incretins that are activated by ingestion of food. Both GIP and GLP-1 deactivate $\alpha$-cells and induces $\beta$-cells of pancreatic islets of Langerhans, thereby lowering the blood glucose level. ${ }^{15-18}$ DPP IV is a GIP and GLP-1 antagonist, respectively inducing the glucagon release and inhibiting the insulin secretion and thus facilitates the onset of hyperglycemia. Most of the drug molecules viz., 


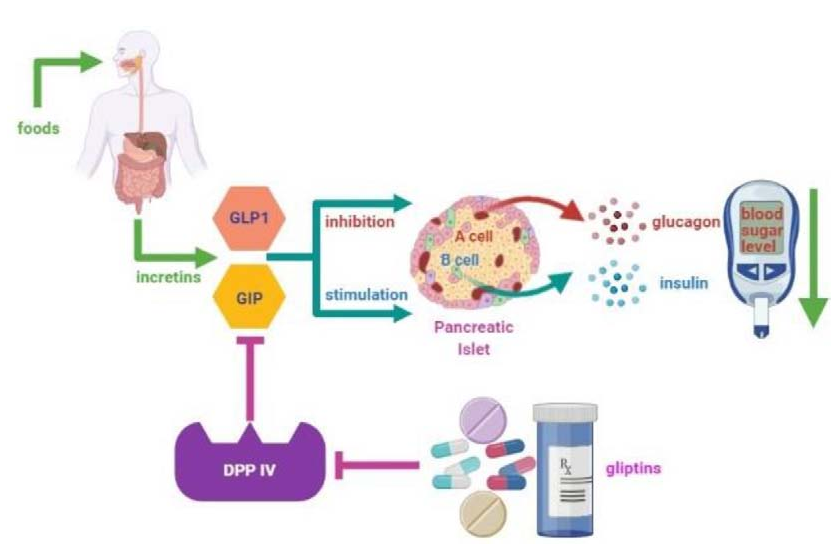

Figure 2: Incretin (GIP and GLP-1) mediated molecular mechanism of DPP IV..$^{15-18}$

sitagliptin, vildagliptin, Saxagliptin, alogliptin, linagliptin, gemigliptin, omrigliptin (Phase III), melogliptin (Phase III), teneligliptin (Phase III), anagliptin (Phase III), gosogliptin (Phase III), carmegliptin (Phase II), RO-0730699 (Phase II), evogliptin (Phase II), E-3024 (Phase I), TAK-100 (Phase I), and peptide mimetics, e.g., Pyr-Val-OH, P-32/98, and NVP-DPP728 inhibit DPP IV and activate incretins resulting homeostasis of body sugar. ${ }^{11,19-21}$ An illustration of the GIP and GLP-1 mediated molecular mechanism of DPP IV, created in the BioRender tool (https://biorender.com/), is shown in Figure 2.

The proposed work aims to identify potential inhibitors against diabetes through molecular interaction of DPP IV with sixteen natural molecules viz., 4,5-dimethyl3-hydroxy-2(5H)-furanone, apigenin, bromelain, caffeic acid, cholecalciferol, dihydrokaempferol 7-o-glucopyranoside, galactomannan, genkwanin, isoimperatorin, luteolin, luteolin 7-o-glucoside, neohesperidin, oleanoic acid, pelargonidin-3-rutinoside, quercetin, and quinic acid using AutoDock Tools (ADT). ${ }^{22}$ Post docking analysis, MD study, metabolism prediction, molecular reactivity, and biological activity spectrum identification of top hits and their comparison with known DPP IV drug molecules favour the outstanding and stable molecular interactions of bromelain within the critical residues of the target protein.

\section{MATERIALS AND METHODS}

Protein 3D structure retrieval and optimization:3D crystal structure $(2.85 \AA)$ of human DPP IV complexed with anagliptin was retrieved from RCSB PDB (https:/ / www. rcsb.org/structure/3WQH). The only apoprotein was taken to prepare 3D files suitable for docking simulation by removing heteroatoms, ions, and molecules viz., 2-acetamido-2-deoxy-beta-D-glucopyranose (NAG),
$\mathrm{N}-[2-(\{2-[(2 \mathrm{~S})-2$-cyanopyrrolidin-1-yl] -2 -oxoethyl $\}$ amino)-2-methylpropyl]-2-methylpyrazolo[1,5-a] pyrimidine-6-carboxamide (SKK), anagliptin, and water molecules. 3D coordinates of anagliptin were carried forward for molecular interactions of phytochemicals. The CHARMm force field was applied to optimize and minimize 3D structure using appropriate algorithms to remove the steric clashes and hindrances. ${ }^{22-26}$

Phytochemicals 3D structure retrieval and optimization: SDF (Standard Data Format) structures of all ligands, namely 4,5-dimethyl-3-hydroxy-2(5H)furanone (CID:62835), apigenin (5280443), bromelain (381623138), caffeic acid (689043), cholecalciferol (5280795), dihydrokaempferol 7-o-glucopyranoside (101683279), galactomannan (439336), genkwanin (5281617), isoimperatorin (68081), luteolin (5280445), luteolin 7-o-glucoside (5280637), neohesperidin (442439), oleanoic acid (485707), pelargonidin-3rutinoside (44256626), quercetin (5280343), and quinic acid (6508) were downloaded PubChem database (http://pubchem.ncbi.nlm.nih.gov). Like-wise 2D structures of known drug molecules in SDF format were also extracted. Conversion of SDF-2D to PDB-3D was done using the BIOVIA discovery studio visualizer. All chemical compounds were energetically optimized and minimized using the same protocol as DPP IV protein.

Molecular docking: 3D molecular interaction of natural compounds and drug molecules with DPP IV was accomplished ADT to find out their potential binding patterns. PDBQT files of DPP IV and various ligands and drug molecules, grid parameter file (GPF), and a docking parameter file (DPF) were created to perform docking experiments. The grid box around the protein molecule was drawn with variable grid points in $\mathrm{x}, \mathrm{y}, \mathrm{z}$ axes and maximum spacing $(1.00 \AA)$ between two consecutive grids. Ten runs for each chemical compound were executed. Minimum free energy of binding $(\Delta \mathrm{G})$ and inhibition constant $(\mathrm{Ki})$ was chosen as selective parameters towards getting one of the bestdocked conformations of ligands into the active site of DPP IV. ${ }^{27-31}$

Molecular dynamics simulation: MD simulation was performed on docked complexes of DPP IV with sitagliptin, neohesperidin, and bromelain at $300 \mathrm{~K}$ at the MM level using GROMACS 5.1.2. ${ }^{32}$ The ligands were extracted from the docked complexes utilizing the gmx grep module. The CGENFF server obtained the topology and forcefield parameter files of the ligand. The topologies were generated for DPP4 utilizing pdb2gmx modules of gromacs, and sitagliptin, neohesperidin, and bromelain using the CGENFF server were merged. ${ }^{33}$ 
All docked complexed were soaked in a dodecahedron box of water molecules with a margin of $10 \AA$. The gmx editconf module was used for creating boundary conditions. The charges on the docked complexes were neutralized by adding $\mathrm{Na}^{+}$and $\mathrm{Cl}^{-}$ions using the gmx genion module to maintain neutrality, preserving the physiological concentration of $0.15 \mathrm{M}$. The system was then minimized for 50,000 steps using the steepest descent algorithm. Finally, the system temperature was raised from $0-300 \mathrm{~K}$ during their equilibration period (100 ps) at constant NVT and NPT. After the equilibration phase, the particle mesh was applied following the Ewald method. ${ }^{34,35}$ Finally, the protein-ligand system was introduced to the $5 \mathrm{~ns}$ of MD simulation performed under identical conditions at $1 \mathrm{bar}$ and temperature of 300K. The gmx rms, gmx rmsf, and gmx sasa modules of GROMACS were used to get the RMSD, RMSF, and SASA of docked molecules. ${ }^{32,33}$

Metabolism prediction: CYP450 sites of metabolism for selected ligands were depicted to elucidate their most probable metabolism using SMARTCyp 3.0. online tool. ${ }^{36,37}$

Biological activity identification: Molecular interactions of small chemical compounds with different biological attributes were achieved through PASS (prediction of activity spectra for substances) online software. The server uses $\mathrm{Pa}$ and $\mathrm{Pi}$ notations, respectively stands for a subclass of active and inactive compounds having values in the range of $0.000-1.000 .{ }^{36,38}$

\section{RESULTS AND DISCUSSION}

\section{Molecular docking}

All ligands and reference drug molecules were docked to DPP IV, getting one of their respective conformers' most substantial binding interactions. Natural ligand molecules exhibit plausible binding having $\Delta G$ values between -5.94 to $-9.86 \mathrm{kcal} / \mathrm{mol}$, and inhibition constant (Ki) in the range of 163.79-1.97 $\mu \mathrm{M}$. Drug molecules depict molecular interactions with $\Delta \mathrm{G}$ values in the range of $-6.97-8.63 \mathrm{kcal} / \mathrm{mol}$, and $\mathrm{Ki}$ between 176.89 to $10.12 \mu \mathrm{M}$. Among drug molecules, sitagliptin ( $\Delta \mathbf{G}$ : $-8.63 \mathrm{kcal} / \mathrm{mol}$, Ki: $10.12 \mu \mathrm{M}$ ) was found one of the best molecules interacting efficiently with target protein DPP IV. Seven ligands, namely apigenin, bromelain, cholecalciferol, isoimperatorin, luteolin, neohesperidin, and oleanoic acid was showing better binding interactions as compared to the sitagliptin. Neohesperidin and bromelain molecules were portrayed an almost similar binding pattern as reflected by their $\Delta \mathbf{G ~ ( - 9 . 8 6 , ~ - 9 . 7 9}$ $\mathrm{kcal} / \mathrm{mol})$ and $\mathrm{Ki}(1.97,2.53 \mu \mathrm{M})$ values, respectively. Henceforth, bromelain, neohesperidin, and sitagliptin were taken into consideration for MD simulation. Post docking simulation analysis of ligand and drug molecules are respectively shown in Table 1 and Table 2 .

Moreover, thirteen residues viz., W17, R88, H89, S172, W178 (H), F171, A173, S175 (H), L177, T119 (H), W120 $(\mathrm{H})$, and $\mathrm{S} 69(\mathrm{H})$ of bromelain (Figure 3), nine residues namely- P325, H326, T267, E324, D265, V266, W178 $(\mathrm{H}), \mathrm{T} 119$, and $\mathrm{W} 179(\mathrm{H})$ of neohesperidin (Figure 4), seven residues viz., S514, Y509, K516 (H), D507, W525 $(\mathrm{H}), \mathrm{Y} 10(\mathrm{H})$, and N524 of sitagliptin (Figure 5) were showing binding interactions with DPP IV. ' $\mathrm{H}$ ' written within brackets exhibits $\mathrm{H}$-bonding making residues providing stability to the docked complexes.

\section{MD simulation}

To assess the stability of docked complexes of top two hits bromelain, and neohesperidin, and known inhibitor sitagliptin with DPP IV, MDS run of $5 \mathrm{~ns}$ duration, were executed using GROMACS package. MD plots for root-mean-square deviation (RMSD), rootmean-square fluctuation (RMSF), solvent-accessible surface area (SASA), and free energy of solvation $(\Delta$ Gsolv) during SASA were generated to evaluate the molecular interaction stability of ligands and protein complexes. ${ }^{25,39-41}$ The binding of ligands into the active site of DPP IV acquires conformational changes to attain stability.

Root-mean-square deviation: RMSD measures the protein's stability and resemblance to its native structure. The average value of RMSD for sitagliptin (black), bromelain (green), and neohesperidin (red) complexed with DPP IV was found $0.14 \mathrm{~nm}, 0.13 \mathrm{~nm}$, and $0.16 \mathrm{~nm}$, respectively. Maximum and minimum deviation of drug and ligand molecules were depicted as 0.08 $0.19 \mathrm{~nm}, 0.07-0.18 \mathrm{~nm}$, and $0.08-0.24 \mathrm{~nm}$, respectively (Figure 6a). The RMSD plot reveals that the bromelainDPP IV complex is more stable than sitagliptin and neohesperidin.

Root-mean-square fluctuation: The mean fluctuation of residues is expressed in terms of the root-meansquare fluctuation (RMSF) pictorial graph that ensures the stability of protein docked with ligand molecules during the entire period of MD simulation. Residues fluctuations at different sites in the RMSF plot are due to the molecular interaction of drug and ligand molecules. The plot reveals that residues fluctuation upon binding with neohesperidin is observed more as compared to drug and bromelain (Figure 6b), dictating that the impact of ligands and inhibitor with DPP IV is not alike during the complete simulation process.

Solvent-accessible surface area and free energy of solvation: The pictorial illustration of a solventaccessible surface area (SASA) uncovers protein's 


\begin{tabular}{|c|c|c|c|c|c|}
\hline S. No. & Ligands & CID & $\Delta \mathrm{G}^{*}(\mathrm{kcal} / \mathrm{mol})$ & ${ }^{\#} \mathrm{~K}_{\mathrm{i}}(\mu M)$ & Residues making H-bonds ${ }^{\wedge}$ \\
\hline 1 & $\begin{array}{l}\text { 4,5-dimethyl-3-hydroxy- } \\
\text { 2(5H)-furanone }\end{array}$ & 62835 & -6.41 & 126.89 & $\begin{array}{c}\mathrm{R} 632-\mathrm{H} 11 \ldots \mathrm{O}, \mathrm{R} 632-\mathrm{H} 21 \ldots \mathrm{O} \\
\mathrm{E} 169-\mathrm{O} 2 \ldots \mathrm{H}\end{array}$ \\
\hline 2 & Apigenin & 5280443 & -9.13 & 6.23 & $\begin{array}{l}\mathrm{R} 632-\mathrm{H} 11 \ldots \mathrm{O}, \mathrm{R} 632-\mathrm{H} 21 \ldots \mathrm{O} \\
\mathrm{D} 265-\mathrm{O} 1 \ldots \mathrm{H}, \mathrm{T} 267-\mathrm{O} 1 \ldots \mathrm{H}\end{array}$ \\
\hline 3 & Bromelain & 381623138 & -9.79 & 2.53 & 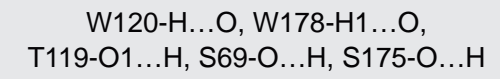 \\
\hline 4 & Caffeic acid & 689043 & -6.12 & 143.76 & 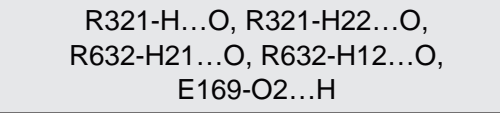 \\
\hline 5 & Cholecalciferol & 5280795 & -9.48 & 3.88 & $\mathrm{R} 88-\mathrm{H} 11 \ldots \mathrm{O}, \mathrm{E} 168-\mathrm{O} 1 \ldots \mathrm{H}$ \\
\hline 6 & $\begin{array}{l}\text { Dihydrokaempferol } \\
\text { 7-O-glucopyranoside }\end{array}$ & 101683279 & -7.41 & 68.31 & 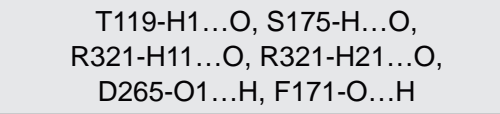 \\
\hline 7 & Galactomannan & 439336 & -7.29 & 105.23 & $\begin{array}{c}\text { R321-H... O, R321-H22 ..O, } \\
\text { H... O-I368, H...O2-E324, H...O2-E371 }\end{array}$ \\
\hline 8 & Genkwanin & 5281617 & -7.24 & 110.15 & R24-H...O, R24-H22 .. O, H... O-I26 \\
\hline 9 & Isoimperatorin & 68081 & -9.32 & 4.68 & $\mathrm{R} 24-\mathrm{H} \ldots \mathrm{O}, \mathrm{R} 24-\mathrm{H} 22 \ldots \mathrm{O}$ \\
\hline 10 & Luteolin & 5280445 & -9.22 & 4.98 & $\begin{array}{c}\text { R321-H...O, R321-H22... O, } \\
\text { R632-H21... O, R632-H12 ... } \\
\text { H...O2-E169 }\end{array}$ \\
\hline 11 & Luteolin 7-O-glucoside & 5280637 & -7.28 & 98.21 & 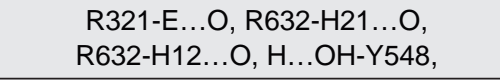 \\
\hline 12 & Neohesperidin & 442439 & -9.86 & 1.97 & W178-H1...O, W179-H...O \\
\hline 13 & Oleanoic acid & 485707 & -8.90 & 8.12 & $\begin{array}{c}\mathrm{R} 523-\mathrm{H} 21 \ldots \mathrm{O}, \mathrm{R} 523-\mathrm{H} 12 \ldots \mathrm{O} \\
\text { H...O2-D519 }\end{array}$ \\
\hline 14 & Pelargonidin-3-rutinoside & 44256626 & -7.97 & 41.32 & $\begin{array}{c}\text { H---O-S425, H...O-E371, H...O1-E371, } \\
\text { H...O1-D265 }\end{array}$ \\
\hline 15 & Quercetin & 5280343 & -7.79 & 67.19 & $\begin{array}{c}\text { R321-H22 ..O, R632-H12... } \\
\text { H ...O2-E169, H...O2-E324, } \\
\text { H...O1-E324 }\end{array}$ \\
\hline 16 & Quinic acid & 6508 & -5.94 & 163.79 & $\begin{array}{l}\text { S593-H...O, H...O1-E168, } \\
\text { H...O1-N673, H...O2-E169 }\end{array}$ \\
\hline
\end{tabular}

*Predicted free energy of binding by ADT

"Predicted inhibition constant by ADT

${ }^{\wedge} \mathrm{H}$-bonds are shown by dotted lines

interactable surface to the solvent molecules. The average value of SASA for sitagliptin, bromelain, and neohesperidin docked with DPP IV was found as $25.24 \mathrm{~nm}^{2}, 24.57 \mathrm{~nm}^{2}$, and $24.7 \mathrm{~nm}^{2}$ (Figure 6c). The SASA findings exhibit that internal residues of DPP IV upon binding of bromelain and neohesperidin are less accessible by the solvent than sitagliptin. The average $\Delta$ Gsolv of DPP IV-sitagliptin, DPP IV-bromelain, and DPP IV-neohesperidin was depicted as -33.21 $\mathrm{kJ} / \mathrm{mol} / \mathrm{nm}^{2},-32.74 \mathrm{~kJ} / \mathrm{mol} / \mathrm{nm}^{2}$, and $-33.66 \mathrm{~kJ} / \mathrm{mol} /$ $\mathrm{nm}^{2}$, respectively (Figure 6d). RMSD, RMSF, SASA, and free energy of solvation plots comparatively favor the potential of bromelain as an inhibitor of the target protein.

\section{CYP450 metabolism prediction}

Knowing the sites of a chemical compound most likely to be metabolized is imperative to facilitate the combinatorial design of new small molecules and thereby to curtail their attrition rate to the pipeline of drug discovery and development. Therefore, CYP450 metabolism of bromelain and neohesperidin was compared with sitagliptin, a known inhibitor of DPP IV based on different scores, energy, COO-dist, Span2end, and 2D-SASA42. The most fprobable CYP3A4 site of metabolism and their feature predictions are shown in Figure $7 \mathrm{a}-\mathrm{c}$ and Table 3 , respectively. ${ }^{42,43}$

\section{Biological activity spectrum identification}

Identifying molecular interactions between lead molecules and their therapeutic targets is crucial in CADD and toxicity evaluation. PASS tool predicts the 


\section{Table 2: Molecular interaction of DPP IV with drug molecules. ${ }^{11}$}

\begin{tabular}{|c|c|c|c|c|c|}
\hline $\begin{array}{l}\text { S. } \\
\text { No. }\end{array}$ & Ligands & CID & $\begin{array}{c}\Delta G \\
\text { (kcal/mol) }\end{array}$ & $\begin{array}{c}K_{i} \\
(\mu M)\end{array}$ & Residues making H-bonds \\
\hline 1 & Sitagliptin & 4369359 & -8.63 & 10.12 & K516-H2 ... O, W525-H...F \\
\hline 2 & Vildagliptin & 6918537 & -7.29 & 79.43 & H88-H2...N, S171-H...O, H...O1-E323 \\
\hline 3 & Saxagliptin & 11243969 & -7.99 & 39.12 & S68-H...O, W119-H...O, H...O-S120 \\
\hline 4 & Alogliptin & 11450633 & -7.42 & 98.54 & Y547-H...O, H...О-E370 \\
\hline 5 & Linagliptin & 10096344 & -7.15 & 103.66 & $\mathrm{~S} 592-\mathrm{H} \ldots \mathrm{O}, \mathrm{H} 702-\mathrm{H} 2 \ldots \mathrm{O}$ \\
\hline 6 & Gemigliptin & 11953153 & -8.56 & 12.56 & $\mathrm{Y} 10-\mathrm{H} \ldots \mathrm{F}, \mathrm{K} 516-\mathrm{H} 2 \ldots \mathrm{N}, \mathrm{H} 702-\mathrm{H} 2 \ldots \mathrm{F}$ \\
\hline 7 & Omrigliptin (Phase III) & 46209133 & -7.84 & 50.84 & S171-H...F, Y509-H...O \\
\hline 8 & Melogliptin (Phase III) & 11623906 & -7.52 & 88.45 & Y509-H...N, S592-H...N, H702-H2 ...N \\
\hline 9 & Tenegliptin (Phase III) & 11949652 & -8.10 & 15.28 & L23-H...O \\
\hline 10 & Anagliptin (Phase III) & 94513473 & -6.74 & 189.20 & H...O-E168 \\
\hline 11 & Gosogliptin (Phase III) & 11516136 & -7.61 & 195.43 & N524-H2 ..F, W525-H...F, S592-H...N \\
\hline 12 & Carmegliptin (Phase II) & 11417567 & -8.42 & 12.99 & K516-H2 ..F, Y714-H...O \\
\hline 13 & RO-0730699 (Phase II) & 22563318 & -8.31 & 13.47 & $\mathrm{R} 87-\mathrm{H} 12 \ldots \mathrm{N}, \mathrm{Y} 714-\mathrm{HH} \ldots \mathrm{N}$ \\
\hline 14 & Evogliptin (Phase II) & 25022354 & -7.73 & 176.89 & 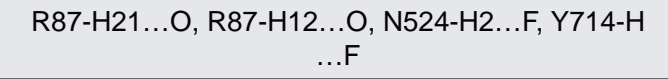 \\
\hline 15 & E-3024 (Phase I) & 23071044 & -7.28 & 85.87 & S592-H...O, H702-H2... O \\
\hline 16 & TAK-100 (Phase I) & 11996845 & -7.02 & 102.76 & H...O2-E, H...O1-E323 \\
\hline \multicolumn{6}{|c|}{ Peptide memetics in early phase of clinical trials } \\
\hline 17 & Pyr-Val-OH & 152416 & -7.01 & 109.98 & S174-H...O, W178-H... \\
\hline 18 & P-32/98 & 6918465 & -6.97 & 115.15 & $\mathrm{R} 318-\mathrm{H} 11 \ldots \mathrm{O}$ \\
\hline 19 & NVP-DPP728 & 9796290 & -7.46 & 96.59 & $\begin{array}{c}\mathrm{Y} 10-\mathrm{H} \ldots \mathrm{N}, \mathrm{R} 87-\mathrm{H} 21 \ldots \mathrm{N}, \mathrm{H} 702-\mathrm{H} 2 \ldots \mathrm{O}, \mathrm{R} 87-\mathrm{H} 12 \ldots \mathrm{N} \\
\text { S592-H ..O }\end{array}$ \\
\hline
\end{tabular}

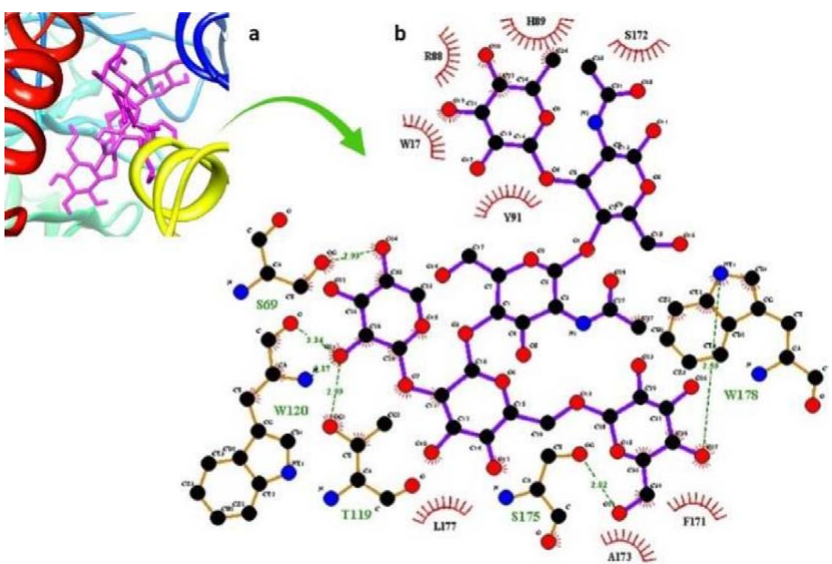

Figure 3: Docked complex of bromelain and DPP IV a) 3D interaction, b) 2D interaction shown by Ligplot ${ }^{+}$. Dashed lines (green) and arcs, respectively, represent $\mathrm{H}$-bonds and hydrophobic contacts.

most plausible interaction of drug-like lead molecules with $>2500$ different biological therapeutic targets using structure-activity relationship analysis, thereby lessen the risk of failure following in vitro and in vivo testing. The PASS tool exhibits the interaction of bromelain, neohesperidin, and sitagliptin with 450, 525, and 59

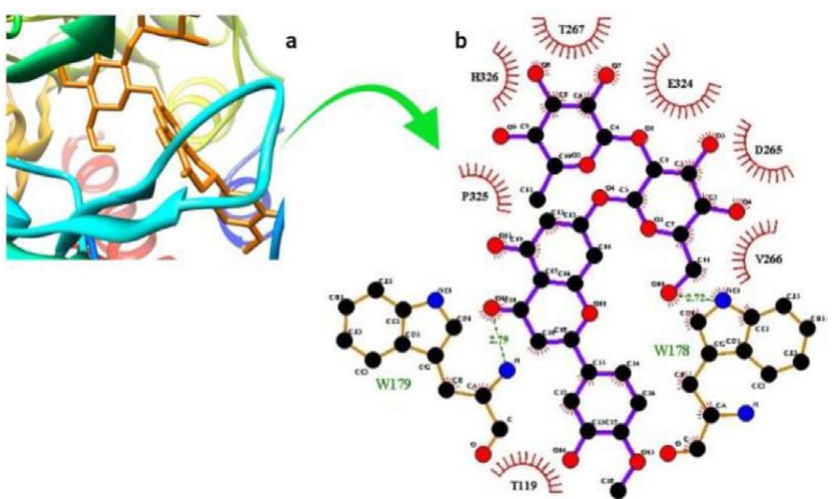

Figure 4: Docked complex of neohesperidin and DPP IV a) 3D interaction, b) 2D interaction shown by Ligplot ${ }^{+}$. Dashed lines (green) and arcs, respectively, represent $\mathrm{H}$-bonds and hydrophobic contacts.

different biological targets, respectively. Antidiabetic activity in terms of $\mathrm{Pa}$ and $\mathrm{Pi}$ values for sitagliptin $(0.595,0.013)$ was found more in comparison to the neohesperidin $(0.567,0.015)$ and bromelain (0.381, 0.049). Moreover, neohesperidin $(0.889,0.001 ; 0.302$, $0.011)$ and bromelain $(0.883,0.001 ; 0.978,0.000)$ also depicts plausible inhibition activity against alpha- and beta-glucosidase while sitagliptin as a specific inhibitor 


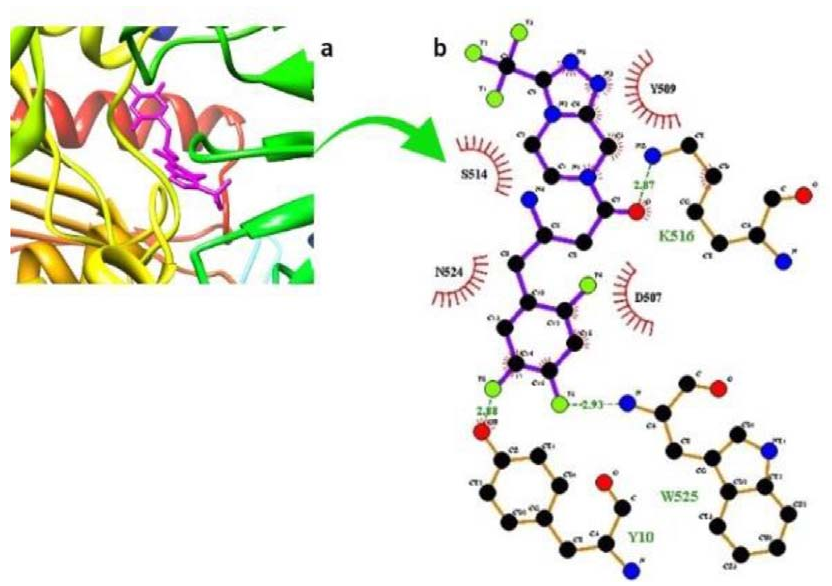

Figure 5: Docked complex of sitagliptin and DPP IV a) 3D interaction, b) 2D interaction shown by Ligplot ${ }^{+}$. Dashed lines (green) and arcs, respectively, represent $\mathrm{H}$-bonds and hydrophobic contacts.
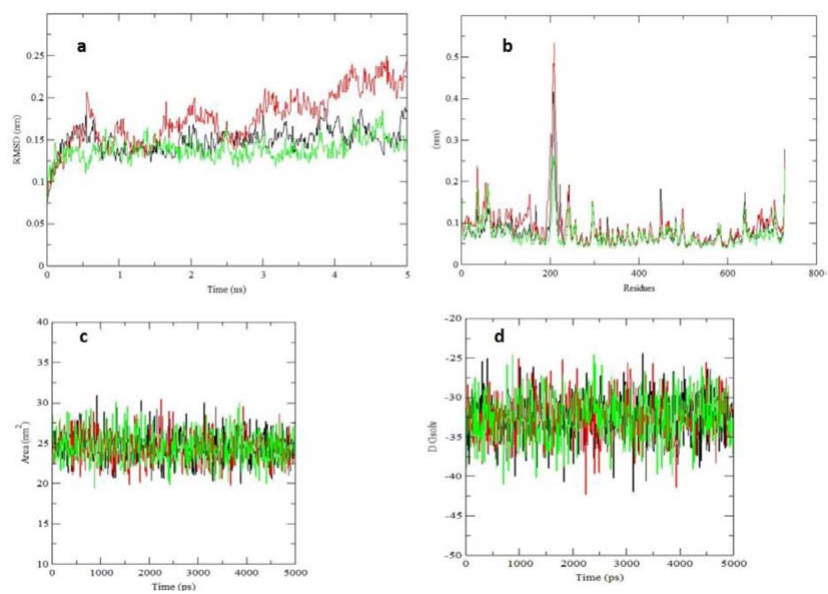

Figure 6: MD simulation of ligands binding to the DPP IV a) RMSD plot as a function of time. Green, red, and black represent bromelain, neohesperidin, and sitagliptin, respectively b) RMSF plot (c) SASA plot, and d) Free energy of solvation. of DPP IV no biological activity predicted against aforesaid targets. Apart from the above targets, antiviral, antineurogenic, antineoplastic, and cardio-protectant activity of both ligands were also predicted within the specified range of $\mathrm{Pa}$ and $\mathrm{Pi}$ values. ${ }^{44}$

Medicines of diabetes except insulin are pharmacotherapeutic molecules recommended for hyperglycemic treatment approved by Food and Drug Administration (FDA). Managing daily lifestyles, including balanced diet and nutrition, regular moderate exercise and yoga, timely eating habits, small frequent meals, and smoking cessation, find difficulties in targeted reduction of glycated hemoglobin $\left(\mathrm{HbA}_{1 \mathrm{c}} \sim 7 \%\right)$ within 12-15 weeks, an antihyperglycemic treatment algorithm is recommended, especially in diabetes type 2 . The holistic approach covers general measures, monotherapy,
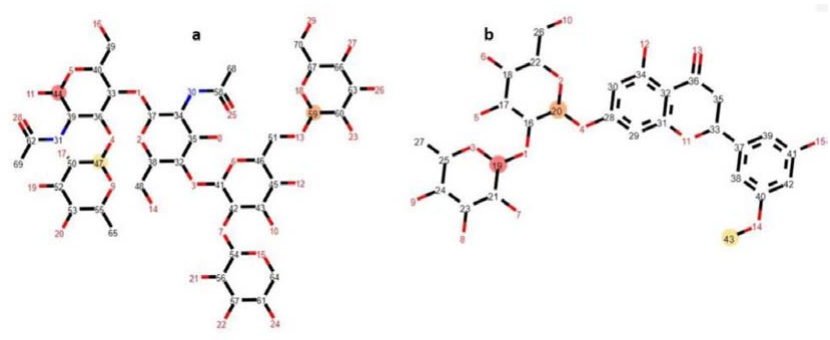

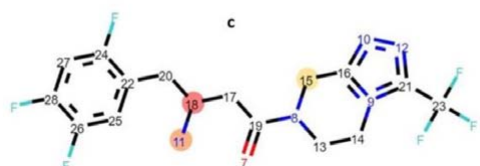

Figure 7: CYP3A4 site metabolism prediction a) bromelain, b) Neohesperidin, and c) sitagliptin. Sites designated as C44, C59, and C47 in bromelain, C19, C20, and C43 in neohesperidin, and $\mathrm{C} 18, \mathrm{~N} 11$, and $\mathrm{C} 15$ are the top-ranked most probable site of metabolism, respectively shown in orange, light orange, and yellow solid spheres.

\begin{tabular}{|c|c|c|c|c|c|c|c|c|}
\hline Compounds & 3A4 ranking & Atom & 3A4 score & "Energy & 2D SASA & Span2end & Relative span & Similarity \\
\hline \multirow[t]{3}{*}{ Bromelain } & 1 & C. 44 & 41.5 & 48.5 & 10.1 & 4 & 0.8 & 0.3 \\
\hline & 2 & C. 59 & 41.5 & 48.5 & 9.6 & 4 & 0.8 & 0.3 \\
\hline & 3 & C. 47 & 41.5 & 48.5 & 9.0 & 4 & 0.8 & 0.3 \\
\hline \multirow[t]{3}{*}{ Neohesperidin } & 1 & C.19 & 41.9 & 48.5 & 9.0 & 4 & 0.8 & 0.3 \\
\hline & 2 & C. 20 & 43.3 & 48.5 & 8.8 & 7 & 0.6 & 0.3 \\
\hline & 3 & C. 43 & 51.5 & 62.2 & 66.4 & 0 & 1.0 & 0.7 \\
\hline \multirow[t]{3}{*}{ Sitagliptin } & 1 & C.18 & 36.0 & 41.1 & 7.8 & 6 & 0.6 & 0.4 \\
\hline & 2 & N.11 & 47.0 & 54.1 & 43.1 & 5 & 0.7 & 0.7 \\
\hline & 3 & C.15 & 53.5 & 59.9 & 27.1 & 5 & 0.7 & 0.3 \\
\hline
\end{tabular}

\#Reference values: Energy (<999), spanzend (<=4), relative span $(0.5-1)$, similarity $(0-1) .4^{42}$ 
dual therapy, triple therapy, and injectable combinations. The general measures deal with taking care of a patient's living pattern, age, duration of illness, risk factors, and comorbidities. In monotherapy, metformin is used, but in contraindication, sulfonylureas are preferred over to it. Dual therapy includes metformin plus anyone oral medicines like sulfonylurea, DPP IV inhibitors, meglitinides, amylin derivatives, $\alpha$-glucosidase inhibitors, basal insulin, and sodium-glucose transport protein-2 inhibitors. Triple therapy includes one more additional oral drug, nightly basal insulin or injectable GLP-1 inducer, and dual therapy medicines. Moreover, metformin, basal insulin, mealtime insulin, or agonists of GLP-1 receptors are administered in combination therapy of diabetes type 2. Antidiabetic medicines classified as insulinotropic and non-insulinotropic are used as monotherapy or combinations depending upon the mode of action. ${ }^{45-50}$

Diabetes is one of the most fatal and complicated diseases in terms of its prevention and cure. Systemic treatments facilitate the management of optimum blood glucose levels apart from halting the onset of other associated morbidities. At the same time, mismanagement in general measures and recommended treatment regimen may prompt the individual to face its dire consequences. So, based on the concept that "prevention is better than cure," it is imperative to decipher the compounds being taken along with the diet or as salads and supplements. Identifying such therapeutic compounds through virtual screening followed by drug-likeness, ADMET filtration, CYP450 metabolism prediction, and propensities of interaction with other therapeutic molecular targets of biological systems having low toxicity are promising preventive strategies against lifestyle-based diseases. The secret of deciphering novel lead molecules based on their molecular recognition is the ability of one ligand to recognize another. Molecular interactions form the basis of molecular recognition. Biological and cellular functions proceed through various chemical interactions between biomacromolecules and ligands. The efficacy of ligands as an inhibitor is evaluated in terms of $\Delta \mathrm{G}$ and $\mathrm{Ki}$ in CADD.

The crucial feature for interacting two molecules at the molecular level includes the 3D shape of molecules, H-bonding, van der Waals interaction, especially dispersion forces, and hydrophobic interactions. The propensity of interacting potential between two molecules may be allosteric or competitive in binding and supported by their shape complementarities. During interactions, energy is released, and thermodynamically it is designated as a negative sign. It means the more significant the energy released, the stronger the binding.

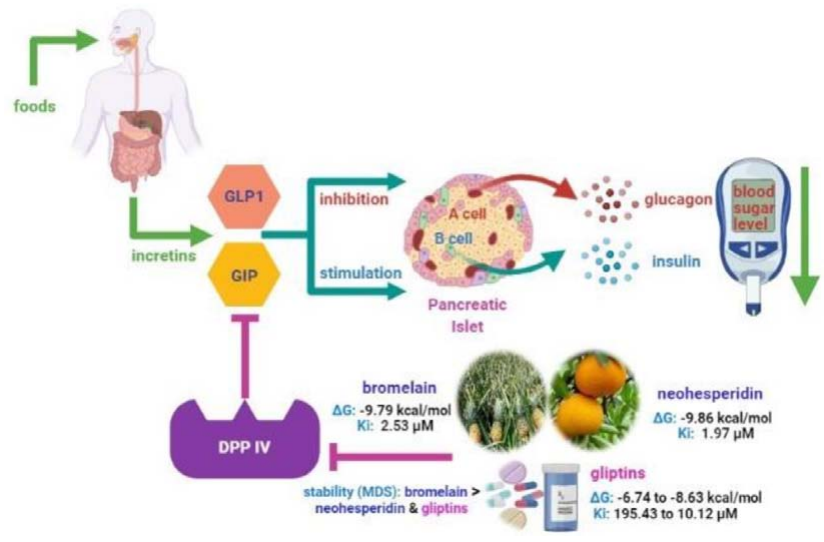

Figure 8: Inhibition of GIP and GLP-1 - mediated DPP IV mechanism by bromelain, neohesperidin, and gliptins.

So, in molecular docking, the ligand-protein complex is always favored by higher energy $(-\Delta \mathrm{G})$ and minimum $\mathrm{Ki}$ values. DPP IV is a promising insulinotropic therapeutic target that influences GIP and GLP-1 incretins directly, thereby dysregulation of pancreatic releases. DPP IV inhibitors are being efficiently used in mono-, dual-, triple-, and combinations therapies against type 2 diabetes. Neohesperidin ( $\Delta \mathrm{G}:-9.86 \mathrm{kcal} / \mathrm{mol}$, Ki: $1.97 \mu \mathrm{M})$ and bromelain $(\Delta \mathrm{G}$ : $-9.79 \mathrm{kcal} / \mathrm{mol}, \mathrm{Ki}: 2.53 \mu \mathrm{M})$ exhibited better inhibition as compared to known DPP IV drug molecules viz., gliptins. Moreover, findings of MDS, CYP metabolism prediction, and interacting pattern against other biological therapeutic targets, bromelain could be comparatively a potent inhibitor against DPP IV. Inhibition of incretins-mediated DPP IV mechanism by bromelain, neohesperidin, and their comparison to gliptins is illustrated in Figure 8.

\section{CONCLUSION}

The present research findings provide the most probable underlying hyperglycemic prevention mechanism by natural phytochemicals through targeting DPP IV. Studies show that DPP IV inhibitors maintain the blood glucose levels in fasting and postprandial, either with monotherapy or combinations with other oral medicines. It also shows significant control in targeted $\mathrm{HbA}_{1 \mathrm{c}}$ and desired sugar level before and after meals, thus playing a significant role in the diabetic treatment algorithm. In the proposed study, seven phytochemicals were identified having inhibition potential greater than gliptins, among which neohesperidin and bromelain exhibited maximum binding. At the molecular level, five H-bonds are formed by W178, S175, T119, W120, and S69 residues of DPP IV with bromelain. Two H-bonds are formed by W178 and W179 residues in docked complex formation of neohesperidin and DPP IV. In 
the case of known inhibitor sitagliptin, three H-bonds by K516, W525, and Y10 residues make the docked complex more stable. Data suggest that the importance of DPP IV inhibitors is multifold in the prevention and cure of diabetes type 2 . In the purview of above, identifying bromelain as a potential inhibitor of DPP IV is promising in preventing and curing diabetes.

\section{ACKNOWLEDGEMENT}

This research has been funded by Scientific Research Deanship at the University of Ha'il-Saudi Arabia through project number RG-20 154.

\section{CONFLICT OF INTEREST}

The authors declare no conflict of interest.

\section{ABBREVIATIONS}

DPP IV: Dipeptidyl Peptidase 4; IDF: International Diabetes Federation; IGT: Impaired Glucose Tolerance; IFG: Impaired Fasting Glycemia; MDS: Molecular Dynamics Simulation; GIP: Glucodependent Insulinotropic Polypeptide; GLP-1: Glucagon-Like Peptide-1; ADT: AutoDock Tools; $\Delta$ G: Free energy of binding; $\mathbf{K}_{\mathrm{i}}$ : Inhibition constant; SDGs: Sustainable Development Goals; CADD: Computer-Aided Drug Design; PASS: Prediction of Activity Spectra for Substances.

\section{REFERENCES}

1. Arneth $B$, Arneth $\mathrm{R}$, Shams M. Metabolomics of Type 1 and Type 2 diabetes. Int J Mol Sci. 2019;20(10):2467. doi: 10.3390/ijms20102467, PMID 31109071.

2. Khan MAB, Hashim MJ, King JK, Govender RD, Mustafa H, Al Kaabi J. Epidemiology of Type 2 diabetes - global burden of disease and forecasted trends. J Epidemiol Glob Health. 2020;10(1):107-11. doi: 10.2991/ jegh.k.191028.001, PMID 32175717.

3. Egan AM, Dinneen SF. What is diabetes? Medicine. 2019;47(1):1-4. doi: 10.1016/j.mpmed.2018.10.002.

4. Szmuilowicz ED, Josefson JL, Metzger BE. Gestational diabetes mellitus. Endocrinol Metab Clin North Am. 2019;48(3):479-93. doi: 10.1016/j. ecl.2019.05.001, PMID 31345518.

5. Yamamoto JM, Donovan LE, Mohammad K, Wood SL. Severe neonatal hypoglycaemia and intrapartum glycaemic control in pregnancies complicated by type 1, type 2 and gestational diabetes. Diabet Med. 2020;37(1):138-46. doi: 10.1111/dme.14137, PMID 31529717.

6. Saeed M, Kausar MA, Singh R, Siddiqui AJ, Akhter A. The role of glyoxalase in glycation and carbonyl stress induced metabolic disorders. Curr Protein Pept Sci. 2020;21(9):846-59. doi: 10.2174/1389203721666200505101734, PMID 32368974.

7. Saeedi P, Petersohn I, Salpea P, Malanda B, Karuranga S, Unwin N, et al. Global and regional diabetes prevalence estimates for 2019 and projections for 2030 and 2045: results from the International Diabetes Federation Diabetes Atlas. 9th ed. Vol. 157; 2019. PMID 107843.

8. Patterson CC, Harjutsalo V, Rosenbauer J, Neu A, Cinek O, Skrivarhaug T, et al. Trends and cyclical variation in the incidence of childhood type 1 diabetes in 26 European centres in the 25 year period 1989-2013:
A multicentre prospective registration study. Diabetologia. 2019;62(3):408-17. doi: 10.1007/s00125-018-4763-3, PMID 30483858.

9. Bommer C, Heesemann E, Sagalova V, Manne-Goehler J, Atun R, Bärnighausen $\mathrm{T}$, et al. The global economic burden of diabetes in adults aged 20-79 years: A cost-of-illness study. Lancet Diabetes Endocrinol. 2017;5(6):423-30. doi: 10.1016/S2213-8587(17)30097-9, PMID 28456416.

10. Robert AA, Al Dawish MA. The worrying trend of diabetes mellitus in Saudi Arabia: An urgent call to action. Curr Diabetes Rev. 2020;16(3):204-10. doi: 10.2174/1573399815666190531093735, PMID 31146665.

11. De S, Banerjee S, Kumar SKA, Paira P. Critical role of dipeptidyl peptidase IV: A therapeutic target for diabetes and cancer. Mini Rev Med Chem. 2019;19(2):88-97. doi: 10.2174/1389557518666180423112154, PMID 29692250.

12. Prasad V, Mailankody S. Assessing Pharmaceutical Research and Development costs-reply. JAMA Intern Med. 2018;178(4):588-9. doi: 10.1001/jamainternmed.2017.8737, PMID 29610885.

13. Barnett A. DPP-4 inhibitors and their potential role in the management of type 2 diabetes. Int J Clin Pract. 2006;60(11):1454-70. doi: 10.1111/j.17421241.2006.01178.x, PMID 17073841.

14. Hussain H, Abbas G, Green IR, Ali I. Dipeptidyl peptidase IV inhibitors as a potential target for diabetes: Patent review (2015-2018). Expert Opin Ther Pat. 2019;29(7):535-53. doi: 10.1080/13543776.2019.1632290, PMID 31203700.

15. Dandona P, Ghanim H, Chaudhuri A. Incretins: Beyond type 2 diabetes. Diabetes Obes Metab. 2018;20;Suppl 1:59-67. doi: 10.1111/dom.13153, PMID 29364583.

16. Chia CW, Egan JM. Incretins in obesity and diabetes. Ann N Y Acad Sci. 2020;1461(1):104-26. doi: 10.1111/nyas.14211, PMID 31392745.

17. Holst JJ. The incretin system in healthy humans: The role of GIP and GLP-1. Metabolism. 2019;96:46-55. doi: 10.1016/j.metabol.2019.04.014, PMID 31029770.

18. Marathe CS, Pham H, Marathe JA, Trahair LG, Huynh L, Wu T, et al. The relationship between plasma GIP and GLP-1 levels in individuals with normal and impaired glucose tolerance. Acta Diabetol. 2020;57(5):583-7. doi: 10.1007/s00592-019-01461-z, PMID 31848710.

19. Sneha P, Doss CGP. Gliptins in managing diabetes - Reviewing computational strategy. Life Sci. 2016;166:108-20. doi: 10.1016/j.Ifs.2016.10.009, PMID 27744054.

20. R Gupta DD. Role of DPP-4 inhibitors in the management of type 2 diabetes. Int J Basic Clin Pharmacol. 2018;7(12):2488. doi: 10.18203/2319-2003. ijbcp20184872.

21. Zheng W, Zhou J, Song S, Kong W, Xia W, Chen L, et al. Dipeptidylpeptidase 4 Inhibitor sitagliptin Ameliorates Hepatic insulin Resistance by Modulating Inflammation and Autophagy in ob/ob Mice. Int $\mathrm{J}$ Endocrinol. 2018;2018:8309723. doi: 10.1155/2018/8309723, PMID 30123267.

22. Morris GM, Goodsell DS, Halliday RS, Huey R, Hart WE, Belew RK, et al. Automated docking using a Lamarckian genetic algorithm and an empirical binding free energy function. J Comput Chem. 1998;19(14):1639-62. doi: 10.1002/(SICI)1096-987X(19981115)19:14<1639::AID-JCC10>3.0.CO;2-B.

23. Watanabe YS, Yasuda Y, Kojima Y, Okada S, Motoyama T, Takahashi R, et al. Anagliptin, a potent dipeptidyl peptidase IV inhibitor: Its single-crystal structure and enzyme interactions. J Enzyme Inhib Med Chem. 2015;30(6):981-8. doi: 10.3109/14756366.2014.1002402, PMID 26147347.

24. Morris GM, Goodsell DS, Huey R, Olson AJ. Distributed automated docking of flexible ligands to proteins: Parallel applications of AutoDock 2.4. J Comput Aided Mol Des. 1996;10(4):293-304. doi: 10.1007/BF00124499, PMID 8877701.

25. Khan FI, Lai D, Anwer R, Azim I, Khan MKA. Identifying novel sphingosine kinase 1 inhibitors as therapeutics against breast cancer. J Enzyme Inhib Med Chem. 2020;35(1):172-86. doi: 10.1080/14756366.2019.1692828, PMID 31752564.

26. Umar AM, Salman A, Haris SM, Kalim KM. Identification of potential lead molecules against dibenzo[a,l]pyrene-induced mammary cancer through targeting cytochrome P450 1A1, 1A2, and 1B1 isozymes. Biointerface Res Appl Chem. 2021;12(1):1096-109. doi: 10.33263/BRIAC121.10961109.

27. Ajijur R, Salman A, Ahmad KMK. Combinatorial design to decipher novel lead molecule against Mycobacterium tuberculosis. Biointerface Res Appl Chem. 2021;11(5):12993-3004. doi: 10.33263/BRIAC115.1299313004. 
28. Khan MKA, Akhtar S, Arif JM. Development of in silico protocols to predict structural insights into the metabolic activation pathways of xenobiotics. Interdiscip Sci Comput Life Sci. 2018;10(2):329-45. doi: 10.1007/s12539017-0237-4, PMID 28527150.

29. Ahmad KMK, Salman A, Al-Khodairy Salman F, Al-Marshad Feras M, Alshahrani Abdulrahman M, Arif Jamal M. Computational Exploration of dibenzo [a, l] pyrene Interaction to DNA and its Bases: possible Implications to Human Health. Biointerface Res Appl Chem. 2020;11(4):11272-83. doi: 10.33263/BRIAC114.1127211283.

30. Khan MKA, Akhtar S, Arif JM. Structural insight into the mechanism of dibenzo[a,I]pyrene and benzo[a]pyrene-mediated cell proliferation using molecular docking simulations. Interdiscip Sci Comput Life Sci. 2018;10(4):653-73. doi: 10.1007/s12539-017-0226-7, PMID 28374118.

31. Khan MKA, Pokharkar NB, Al-Khodairy FM, Al-Marshad FM, Arif JM. Structural perspective on molecular interaction of $\lg G$ and $\lg A$ with spike and envelope proteins of SARS-CoV-2 and its implications to non-specific immunity. Biointerface Res Appl Chem. 2020 Nov 15;11(3):10923-39. doi: 10.33263/BRIAC113.1092310939.

32. Van Der Spoel D, Lindahl E, Hess B, Groenhof G, Mark AE, et al. GROMACS: fast, flexible, and free. J Comput Chem. 2005;26(16):1701-18. doi: 10.1002/ jcc.20291, PMID 16211538.

33. Fischer NM, Van Maaren PJ, Ditz JC, Yildirim A, Van der Spoel D. Properties of organic liquids when simulated with long-range Lennard-Jones interactions. J Chem Theory Comput. 2015;11(7):2938-44. doi: 10.1021/acs.jctc.5b00190, PMID 26575731.

34. Petersen HG. Accuracy and efficiency of the particle mesh Ewald method. J Chem Phys. 1995;103(9):3668-79. doi: 10.1063/1.470043.

35. Stenberg S, Stenqvist B. An exact Ewald summation method in theory and practice. J Phys Chem A. 2020;124(19):3943-6. doi: 10.1021/acs. jpca.0c01684, PMID 32285671.

36. Sharma N, Faisal M, Alatar AA, Khan MKA, Ahmad S, Akhtar S. Design, SAR, and metabolism study of Crucifereae family compound (Spirobrassinin) and its analogs for antiangiogenic potential targeting Hsp90. Curr Proteomics. 2020;18(3):362-79. doi: 10.2174/1570164617999200731000719.

37. Olsen L, Montefiori M, Tran KP, Jørgensen FS. SMARTCyp 3.0: Enhanced cytochrome P450 site-of-metabolism prediction server. Bioinformatics. 2019;35(17):3174-5. doi: 10.1093/bioinformatics/btz037, PMID 30657882.

38. Dmitriev AV, Filimonov DA, Rudik AV, Pogodin PV, Karasev DA, Lagunin AA, et al. Drug-drug interaction prediction using PASS SAR QSAR Environ Res. 2019;30(9):655-64. doi: 10.1080/1062936X.2019.1653966, PMID 31482727.

39. Ali S, Khan FI, Mohammad T, Lan D, Hassan MI, Wang Y. Identification and evaluation of inhibitors of lipase from Malassezia restricta using virtual high-throughput screening and Molecular Dynamics studies. Int $\mathrm{J}$ Mol Sci. 2019;20(4):884. doi: 10.3390/ijms20040884, PMID 30781686.

40. Kuzmanic A, Zagrovic B. Determination of ensemble-average pairwise root mean-square deviation from experimental B-factors. Biophys J. 2010;98(5):861-71. doi: 10.1016/j.bpj.2009.11.011, PMID 20197040.

41. Páll S, Zhmurov A, Bauer P, Abraham M, Lundborg M, Gray A, et al. Heterogeneous parallelization and acceleration of molecular dynamics simulations in GROMACS. J Chem Phys. 2020;153(13):134110. doi: 10.1063/5.0018516.

42. Liu R, Liu J, Tawa G, Wallqvist A. 2D SMARTCyp reactivity-based site of metabolism prediction for major drug-metabolizing cytochrome P450 enzymes. J Chem Inf Model. 2012;52(6):1698-712. doi: 10.1021/ci3001524, PMID 22631565.

43. Alreshidi FS, Ginawi IA, Hussain MA, Arif JM. Piperaquine- and aspirinmediated protective role of HSP70 and HSP90 as modes to strengthen the natural immunity against potent SARS-CoV-2. Biointerface Res Appl Chem. 2021;11(4):12364-79. doi: 10.33263/BRIAC114.1236412379.

44. Pogodin PV, Lagunin AA, Filimonov DA, Poroikov VV. PASS Targets: Ligand-based multi-target computational system based on a public data and naïve Bayes approach. SAR QSAR Environ Res. 2015;26(10):783-93. doi: 10.1080/1062936X.2015.1078407, PMID 26305108.

45. Blonde L. Current antihyperglycemic treatment guidelines and algorithms for patients with type 2 diabetes mellitus. Am J Med. 2010;123(3);Suppl:S12-8. doi: 10.1016/j.amjmed.2009.12.005, PMID 20206727.

46. Owens DR, Monnier L, Barnett AH. Future challenges and therapeutic opportunities in type 2 diabetes: changing the paradigm of current therapy. Diabetes Obes Metab. 2017;19(10):1339-52. doi: 10.1111/dom.12977, PMID 28432748.

47. Makrilakis K. The role of DPP-4 inhibitors in the treatment algorithm of type 2 diabetes mellitus: When to select, what to expect. Int J Environ Res Public Health. 2019;16(15):2720. doi: 10.3390/ijerph16152720, PMID 31366085.

48. Mosslemi M, Park HL, McLaren CE, Wong ND. A treatment-based algorithm for identification of diabetes type in the National Health and Nutrition Examination Survey. Cardiovasc Endocrinol Metab. 2020;9(1):9-16. doi: 10.1097/XCE.0000000000000189, PMID 32104786.

49. Moreira RO, Cobas R, Lopes Assis Coelho RC. Combination of basal insulin and GLP-1 receptor agonist: is this the end of basal insulin alone in the treatment of type 2 diabetes? Diabetol Metab Syndr. 2018;10(1):26. doi: 10.1186/s13098-018-0327-4, PMID 29636825.

50. Glossmann HH, Lutz OMD. Metformin and aging: A review. Gerontology. 2019;65(6):581-90. doi: 10.1159/000502257, PMID 31522175.

\section{SUMMARY}

DM2 is the most prevalent disease irrespective of developing or developed socioeconomic status and is the culprit for millions of deaths each year worldwide. The persistence of DM2 over a long period leads towards irreparable damage of vital organs and induction of various microvascular and macrovascular complications viz., retinopathy, gastroparesis, nephropathy, erectile dysfunction, bladder dysfunction, peripheral neuropathy, cerebrovascular disease, coronary heart disease, Monckeberg arteriosclerosis, and peripheral artery diseases. Despite the availability of many preventive and therapeutic drugs, it is an arduous task to find total control and cure diabetes. Therefore, it is crucial to inhibit molecular targets responsible for increased blood glucose levels through natural ingredients found in our dietary meals. Towards this direction, DPP IV was selected as a therapeutic target. Identifying potential DPP IV inhibitors comparable to its known drug molecules, molecular interaction studies with sixteen natural dietary molecules were carried out using ADT followed by MD simulation, CYP450 metabolism prediction, and biological activity depiction. Based on the $\Delta \mathrm{G}$ and Ki criteria of ADT, bromelain and neohesperidin were found as the top two ligand hits and sitagliptin as a top reference drug molecule. RMSD, RMSF, SASA, and $\Delta$ Gsolv of MD simulation analyses depicted bromelainDPP IV docked complex more stable than both neohesperidin and sitagliptin. CYP450 metabolism and molecular interaction with various biological targets felicitate bromelain as a promising therapeutic molecule against DPP IV. 


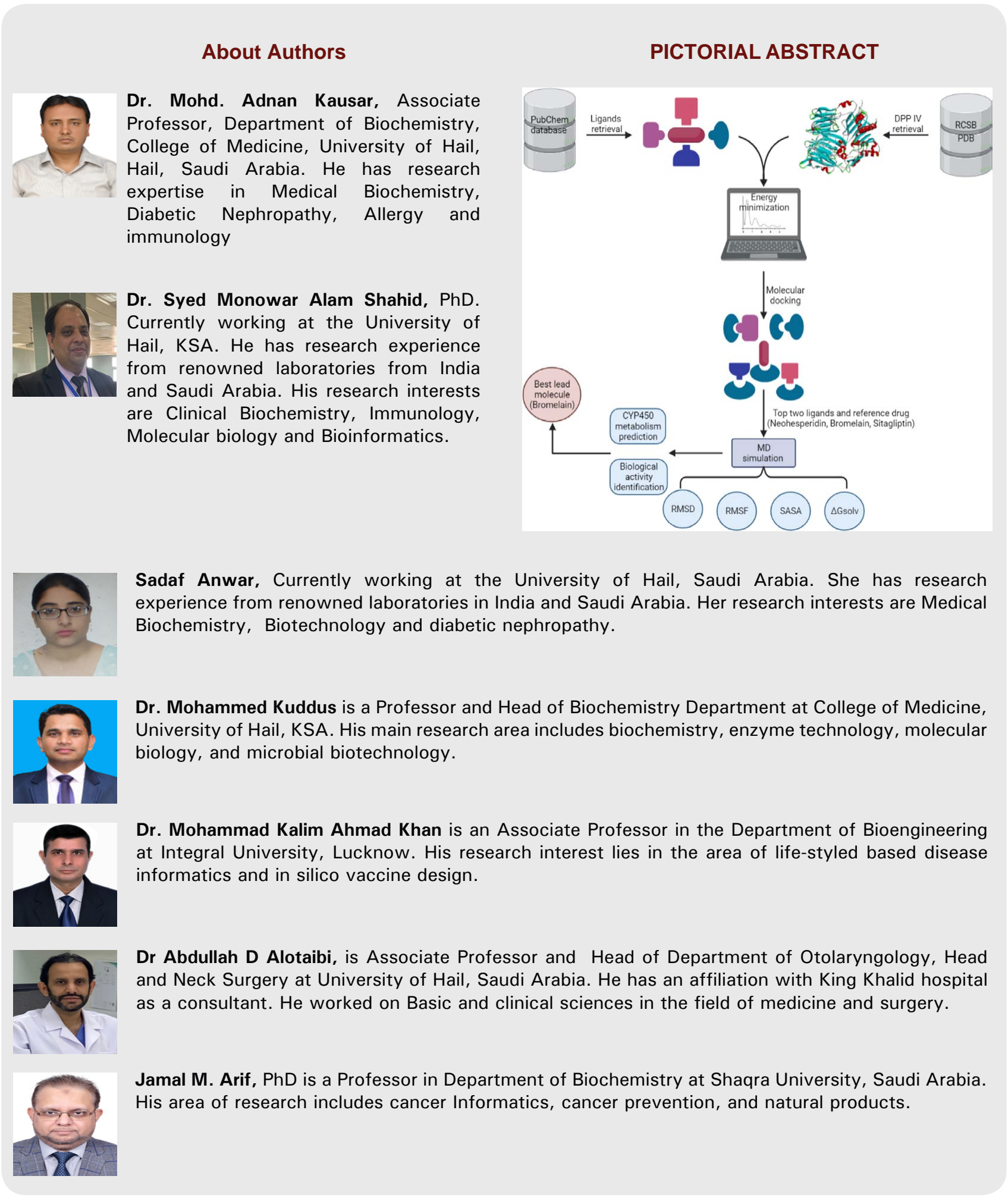

Cite this article: Kausar MA, Shahid SMA, Anwar S, Kuddus M, Khan MKA, Arif JM, Alotaibi AD. Identifying Natural Therapeutics against Diabetes via Inhibition of Dipeptidyl Peptidase 4: Molecular Docking and MD Simulation Study. Indian J of Pharmaceutical Education and Research. 2022;56(1s):s21-s31. 